\title{
One-Year Mortality in Patients with Cancer Cachexia: Association with Albumin and Total Protein
}

\author{
Xiao-Yue Liu ${ }^{1-4, *}$ \\ Xi Zhang $\mathbb{D}^{1-3,5, *}$ \\ Guo-Tian Ruan ${ }^{1-3}$ \\ Kang-Ping Zhang ${ }^{1-3}$ \\ Meng Tang ${ }^{1-3}$ \\ Qi Zhang ${ }^{1-3}$ \\ Meng-Meng Song ${ }^{1-3}$ \\ Xiao-Wei Zhang ${ }^{1-3}$ \\ Yi-Zhong Ge $\mathrm{Gl}^{\mathrm{l}-3}$ \\ Ming Yang ${ }^{1-3}$ \\ Hong-Xia Xu ${ }^{6}$ \\ Chun-Hua Song $\mathbb{D}^{7}$ \\ Han-Ping Shi $\mathbb{D}^{1-3}$
}

'Department of Gastrointestinal Surgery/ Department of Clinical Nutrition, Beijing Shijitan Hospital, Capital Medical University, Beijing, I00038, People's Republic of China;

${ }^{2}$ Department of Oncology, Capital Medical University, Beijing, 100038, People's

Republic of China; ${ }^{3}$ Beijing International

Science and Technology Cooperation Base

for Cancer Metabolism and Nutrition,

Beijing, I00038, People's Republic of China;

${ }^{4}$ School of Clinical Medicine, Hebei

University, Baoding, 071000, People's

Republic of China; ${ }^{5}$ Department of

Radiotherapy, Affiliated Hospital of Hebei

University, Baoding, 071000, People's

Republic of China; ${ }^{6}$ Department of Clinical

Nutrition, Daping Hospital, Army Medical

University, Chongqing, 400042, People's

Republic of China; ${ }^{7}$ Department of

Epidemiology, College of Public Health,

Zhengzhou University, Zhengzhou, Henan,

45000I, People's Republic of China

*These authors contributed equally to this work

Correspondence: Han-Ping Shi

Department of Gastrointestinal Surgery/

Department of Clinical Nutrition, Beijing

Shijitan Hospital, Capital Medical

University, Beijing, 100038, People's

Republic of China

Email shihp@ccmu.edu.cn
Purpose: Serum albumin can indicate the onset of cancer cachexia, provide information about a patient's nutritional status, and serve as a biomarker for the prognosis of patients with cancer cachexia. However, the relationship between serum albumin levels and mortality in patients with cancer cachexia remains unclear. We aimed to examine the association of albumin and total protein with 1-year mortality in patients with cancer cachexia.

Patients and Methods: We conducted a nested case-control study using data from a multicenter cancer clinical survey from 2013 to 2018. In total, 266 patients with cancer cachexia who survived for $<1$ year and 266 patients who survived for $\geq 1$ year were included in this study. The participants were matched by age, sex, tumor type, tumor stage, and hospital site. The crude and adjusted risks of 1-year survival were estimated using odds ratios (ORs) and 95\% confidence intervals (95\% CIs) using logistic regression, with or without adjustment for covariates.

Results: Logistic regression analysis revealed a significantly negative linear association between albumin level and 1-year mortality in patients with cancer cachexia $(p<0.001)$. An L-shaped relationship existed between total protein and 1-year mortality, with a turning point at $70.4 \mathrm{~g} / \mathrm{L}$. When albumin was divided into quartiles, Q3 (OR: 0.40; 95\% CI: 0.24, $0.68 ; \mathrm{p}<0.001$ ) and Q4 (OR: 0.33; 95\% CI: 0.19, 0.55; p < 0.001) were associated with higher 1-year survival than Q1 among patients with cancer cachexia. When total protein was divided into quartiles, Q2 (OR: 0.38; 95\% CI: 0.23, 0.64; $\mathrm{p}<0.001$ ), Q3 (OR: 0.57; 95\% CI: $0.33,0.96 ; \mathrm{p}=0.035$ ), and Q4 (OR: $0.43 ; 95 \% \mathrm{CI}: 0.25,0.72 ; \mathrm{p}=0.002$ ) were associated with higher 1-year survival than Q1 among patients with cancer cachexia.

Conclusion: Serum albumin and total protein may predict 1-year survival. Future clinical studies should lead to a more comprehensive understanding of the effects of serum protein levels in patients with cancer cachexia.

Keywords: nutrition, survival, death, cachectic patients

\section{Introduction}

Cancer cachexia is defined as a multifactorial and multi-organ syndrome characterized by the loss of skeletal muscle mass (with or without loss of adipose tissue), which cannot be fully reversed by conventional nutritional support. ${ }^{1}$ In recent years, cancer cachexia has increasingly been seen as a systemic phenomenon that affects various organs, such as the liver and myocardial tissue. ${ }^{2}$ Cachexia is closely related to anorexia, inflammation, insulin resistance, and decreased protein levels, ${ }^{3}$ which can lead to progressive functional impairment, treatment-related complications, poor quality of life, and cancer-related death. ${ }^{4}$ Its pathophysiology is characterized by a negative protein and energy balance. However, there are no clear clinical 
guidelines to effectively combat the progressive tissue loss associated with cachexia. Cancer cachexia occurs mostly in advanced cancers, with more than half of patients with cancer having cachexia in the later stages, and $>10 \%$ of patients die with or from it. ${ }^{5}$

Studies have shown that cachexia can be diagnosed when weight loss in the past 12 months is $\geq 5 \%$, and the physiological variables of patients match at least three of the following five criteria: decreased muscle strength, fatigue, anorexia, low fat-free mass index (FFMI), and abnormal blood profile. ${ }^{5}$ Albumin and total protein are two variables that reflect an individual's nutritional status and disease severity. Additionally, albumin can serve as an indicator of the inflammatory response and is considered a highly sensitive marker of a patient's nutritional status. ${ }^{6}$ Serum albumin and total protein can be used to define cancer cachexia and cancer-related malnutrition; patients with cachexia have lower total protein and albumin levels than those without cachexia. ${ }^{5}$ Serum albumin may serve as a prognostic factor for treatment outcomes and compliance in patients with advanced cancer. $^{7}$

Although a reduction in albumin and total protein levels are associated with the diagnosis of cancerrelated cachexia, no studies have shown that albumin and total protein can predict mortality in patients with cancer cachexia. Here, we describe a nested case-control study that was conducted to explore the association between serum albumin and total protein levels and 1-year mortality in patients with cancer cachexia.

\section{Patients and Methods}

\section{Methods}

\section{Study Population and Design}

This was a retrospective analysis derived from a multicenter cancer clinical trial conducted from 2013 to 2018 (NO ChiCTR1800020329, http://www.chictr.org.cn/).

The inclusion and exclusion criteria for the multicenter trial project have been described in previous studies. ${ }^{8}$ This study was approved by the medical ethical review committee of the registration hospital and was conducted in accordance with the Declaration of Helsinki.

\section{Patient Characteristics}

Patients were enrolled in the study, and the following demographic data were collected: age, sex, tumor stage, tumor type, previous treatment, nutrition support, family history of cancer, total protein, albumin, hemoglobin $\mathrm{Hb}$, white blood cell (WBC) count, neutrophil count, lymphocyte count, red blood cell (RBC) count, platelet (PLT) count, body mass index (BMI), mid-arm circumference (MAC), thickness of triceps skinfold (TSF), handgrip strength (HGS), and calf circumference (CC). The pathological stage of the tumor was defined according to the American Joint Committee on Cancer (AJCC) TNM (tumor node metastasis) staging system (8th edition). ${ }^{9}$

\section{Diagnosis of Cancer Cachexia}

Cancer cachexia was diagnosed according to the international consensus standards: more than 5\% loss of stable body weight over the past 6 months, or a BMI less than $20 \mathrm{~kg} / \mathrm{m}^{2}$ and ongoing weight loss of more than $2 \%$ or sarcopenia that has not yet entered the refractory stage. ${ }^{1}$

\section{Laboratory Measurements}

Laboratory measurements included nutrition and inflammatory markers, and all blood tests were performed on patients who fasted for at least $9 \mathrm{~h}$ within $24 \mathrm{~h}$ of hospitalization.

\section{Anthropometric Measurements and Assessment of Lifestyle Factors}

BMI was calculated as follows: BMI $\left(\mathrm{kg} / \mathrm{m}^{2}\right)=$ weight $(\mathrm{kg}) /$ height $^{2}\left(\mathrm{~m}^{2}\right)$. The MAC and CC were measured using a plastic metric tape measure. For the TSF, the skin was grabbed $2 \mathrm{~cm}$ above the midpoint of the right upper arm with a thumb and index finger to create a skinfold, after which the calipers were placed at the midpoint of the skinfold. ${ }^{10}$ The HGS of the dominant hand was measured using a Jamar dynamometer. Patient records were used to obtain information on smoking status, alcohol consumption, and tea consumption.

\section{Nested Case-Control Study}

This analysis used data from a nested control study (Figure 1). We chose the 1-year time point because it is the standard time-frame used in studies of chronic conditions such as congestive heart failure. ${ }^{11}$ In the case group, patients diagnosed with cancer cachexia in the hospital survived for less than 1 year. The patients in the control group were diagnosed with cancer cachexia in the hospital and survived for more than 1 year, and their data were matched to the case group in terms of sex, 


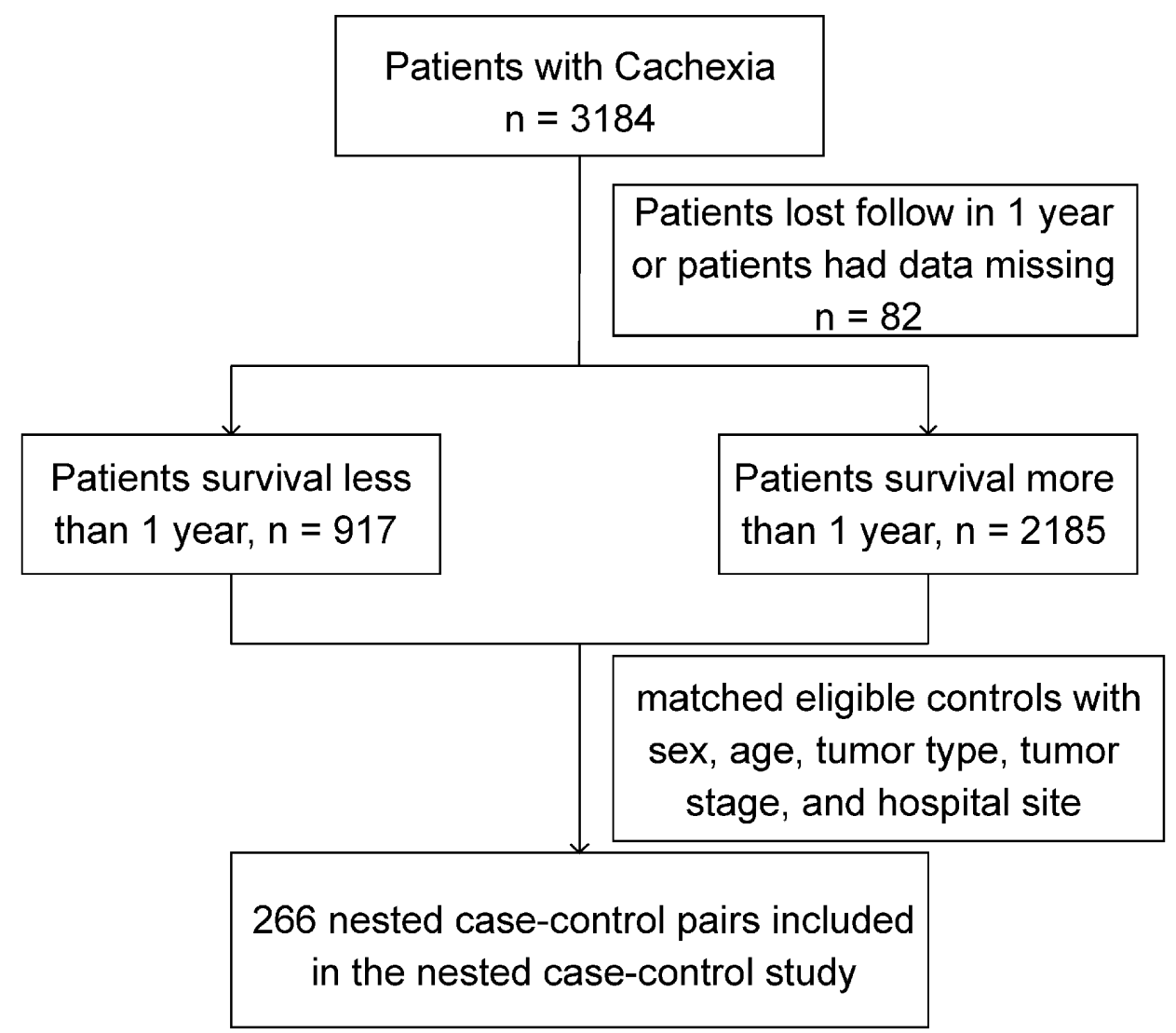

Figure I Flowchart.

Note: This nested case-control study was based on a multicenter clinical investigation.

age, tumor type, tumor stage, and hospital site. A total of 266 patients who survived less than 1 year after cachexia diagnosis and 266 matched controls with available baseline information were included in the analysis, and their laboratory and anthropometric data were collected.

\section{Variable Definitions}

We used clinical cut-off values for albumin, total protein, lymphocyte, neutrophils, WBC, PLT, Hb, BMI, TSF, and HGS as the threshold values. The threshold value of NLR was obtained using a receiver operating characteristic (ROC) curve. Albumin was grouped as abnormal albumin level $\leq 35 \mathrm{~g} / \mathrm{L}$ and normal albumin level $>35 \mathrm{~g} / \mathrm{L}$. Total protein was grouped as abnormal total protein $\leq 60 \mathrm{~g} / \mathrm{L}$ and normal total protein level $>60 \mathrm{~g} / \mathrm{L}$.

\section{Statistical Analysis}

Baseline characteristics were expressed as mean \pm standard deviation (SD) for continuous variables and proportional to categorical variables. When comparing the differences between the case and control groups, the double-sample Wilcoxon rank-sum test or doublesample $t$-test was used for continuous variables, while the chi-squared test was used for categorical variables. The odds ratios (ORs) and 95\% confidence intervals (95\% CIs) for 1-year survival in patients with cancer cachexia were calculated using modeling risk factors as continuous variables, and the quartile albumin and total protein were modeled using conditional logistic regression, with and without adjustment for correcting variables. The cutoff values of total protein and albumin were based on pre-existing clinical standards. ${ }^{12}$ As additional exploratory analyses, possible modifications of the relationship between 1-year mortality and total protein and albumin levels were also assessed.

A two-tailed $\mathrm{p}<0.05$ was considered to be statistically significant in all analyses. All analyses were performed using $\mathrm{R}$ software (version 4.0.4, $\mathrm{R}$ Foundation for Statistical Computing, Vienna, Austria; https://www.r-pro ject.org/). 


\section{Results}

\section{Characteristics of Patients}

A total of 266 matched pairs were included in the analysis.

Patients who survived less than 1 year tended to have higher
WBC, neutrophils, and PLT, and had lower albumin, total protein, $\mathrm{Hb}$, lymphocyte, RBC, BMI, MAC, TSF, HGS, and $\mathrm{CC}$, respectively, with more nutritional support at baseline than control subjects (Table 1).

Table I Detailed Baseline Characteristics of the Study Population

\begin{tabular}{|c|c|c|c|}
\hline \multirow[t]{2}{*}{ Characteristics } & Survival Less Than I Year & Survival More Than I Year & \multirow[t]{2}{*}{$P$ value } \\
\hline & $n=266$ & $n=266$ & \\
\hline Age & $59.65 \pm 9.73$ & $59.79 \pm 9.71$ & 0.873 \\
\hline \multicolumn{4}{|l|}{ Gender (\%) } \\
\hline Male & $169(63.5)$ & $169(63.5)$ & 1 \\
\hline Female & $97(36.5)$ & $97(36.5)$ & 1 \\
\hline Tumor type (\%) & & & 1 \\
\hline Lung cancer & $62(23.3)$ & $62(23.3)$ & \\
\hline Gastric cancer & $65(24.4)$ & $65(24.4)$ & \\
\hline Esophagus cancer & $34(12.8)$ & $34(12.8)$ & \\
\hline Colorectal cancer & $62(23.3)$ & $62(23.3)$ & \\
\hline Others* & $43(16.2)$ & $43(16.2)$ & \\
\hline Tumor stage (\%) & & & 1 \\
\hline I & $8(3.0)$ & $8(3.0)$ & \\
\hline II & $31(11.7)$ & $31(11.7)$ & \\
\hline III & 87 (32.7) & $87(32.7)$ & \\
\hline IV & $140(52.6)$ & $140(52.6)$ & \\
\hline \multicolumn{4}{|l|}{ Treatment (\%) } \\
\hline Surgery & $62(23.3)$ & $70(26.3)$ & $<0.001$ \\
\hline Chemotherapy & $125(47.0)$ & $157(59.0)$ & $<0.001$ \\
\hline Radiotherapy & $12(4.5)$ & $4(1.5)$ & $<0.001$ \\
\hline Others** & $67(25.2)$ & $35(13.2)$ & $<0.001$ \\
\hline Family history of cancer, n (\%) & $43(16.2)$ & $39(14.7)$ & 0.719 \\
\hline Nutrition support, n (\%) & $184(69.2)$ & $217(81.6)$ & 0.001 \\
\hline \multicolumn{4}{|l|}{ Laboratory measurements } \\
\hline Total Protein, g/L & $64.91 \pm 8.43$ & $67.38 \pm 6.86$ & $<0.001$ \\
\hline Albumin, $g / L$ & $35.22 \pm 5.33$ & $38.00 \pm 4.84$ & $<0.001$ \\
\hline $\mathrm{Hb}, \mathrm{g} / \mathrm{L}$ & || $3.74 \pm 20.8 \mid$ & $120.46 \pm 17.98$ & $<0.001$ \\
\hline WBC, $\times 10^{9} / \mathrm{L}$ & $7.89 \pm 4.05$ & $6.45 \pm 3.18$ & $<0.001$ \\
\hline Neutrophils, $\times 10^{9} / \mathrm{L}$ & $5.84 \pm 3.75$ & $4.34 \pm 2.76$ & $<0.001$ \\
\hline Lymphocyte, $\times 10^{9} / \mathrm{L}$ & $1.27 \pm 0.66$ & $1.48 \pm 0.63$ & $<0.001$ \\
\hline $\mathrm{RBC}, \times 10^{12} / \mathrm{L}$ & $3.92 \pm 0.72$ & $4.14 \pm 0.60$ & $<0.001$ \\
\hline $\mathrm{PLT}, \times 10^{9} / \mathrm{L}$ & $258.13 \pm 115.15$ & $234.93 \pm 95.18$ & 0.012 \\
\hline \multicolumn{4}{|l|}{ Anthropometric measurements } \\
\hline $\mathrm{BMI}, \mathrm{kg} / \mathrm{m}^{2}$ & $20.14 \pm 2.9 \mid$ & $21.21 \pm 3.23$ & $<0.001$ \\
\hline $\mathrm{MAC}, \mathrm{cm}$ & $24.49 \pm 3.28$ & $25.30 \pm 3.57$ & 0.007 \\
\hline TSF mm & $12.49 \pm 6.63$ & $14.73 \pm 7.23$ & $<0.001$ \\
\hline HGS, kg & $22.19 \pm 9.70$ & $24.25 \pm 8.37$ & 0.009 \\
\hline $\mathrm{CC}, \mathrm{cm}$ & $30.92 \pm 3.53$ & $31.89 \pm 3.61$ & 0.002 \\
\hline
\end{tabular}

Notes: Continuous variables are presented as mean \pm standard deviation, and categorical variables are presented as numbers (percentages). ${ }^{*} O$ ther types: liver cancer, breast cancer, bladder cancer, pancreatic cancer, prostate cancer, ovarian cancer, and nasopharyngeal cancer. **Other treatments: targeted therapy, immunotherapy, endocrinotherapy and treatment of complications. Differences in baseline characteristics were compared using the $\chi^{2}$ test for categorical variables and the two-sample $t$-test for continuous variables. Abbreviations: Hb, hemoglobin; WBC, white blood cell; RBC, red blood cell; PLT, platelet; BMI, body mass index; MAC, mid-arm circumference; TSF, triceps skin fold; HGS, handgrip strength; CC, calf circumference. 


\section{Association of Albumin and Total Protein with I-Year Mortality in Patients with Cancer Cachexia}

There was a significantly negative linear association between albumin and 1-year mortality in patients with cancer cachexia (OR: 0.90; 95\% CI: 0.87, 0.93, $\mathrm{p}<0.001$ ) (Figure 2A). We identified an L-shaped pattern between total protein and 1-year mortality (OR: 0.96; 95\% CI: 0.94, 0.98, p<0.001) (Figure 2C). The 1-year
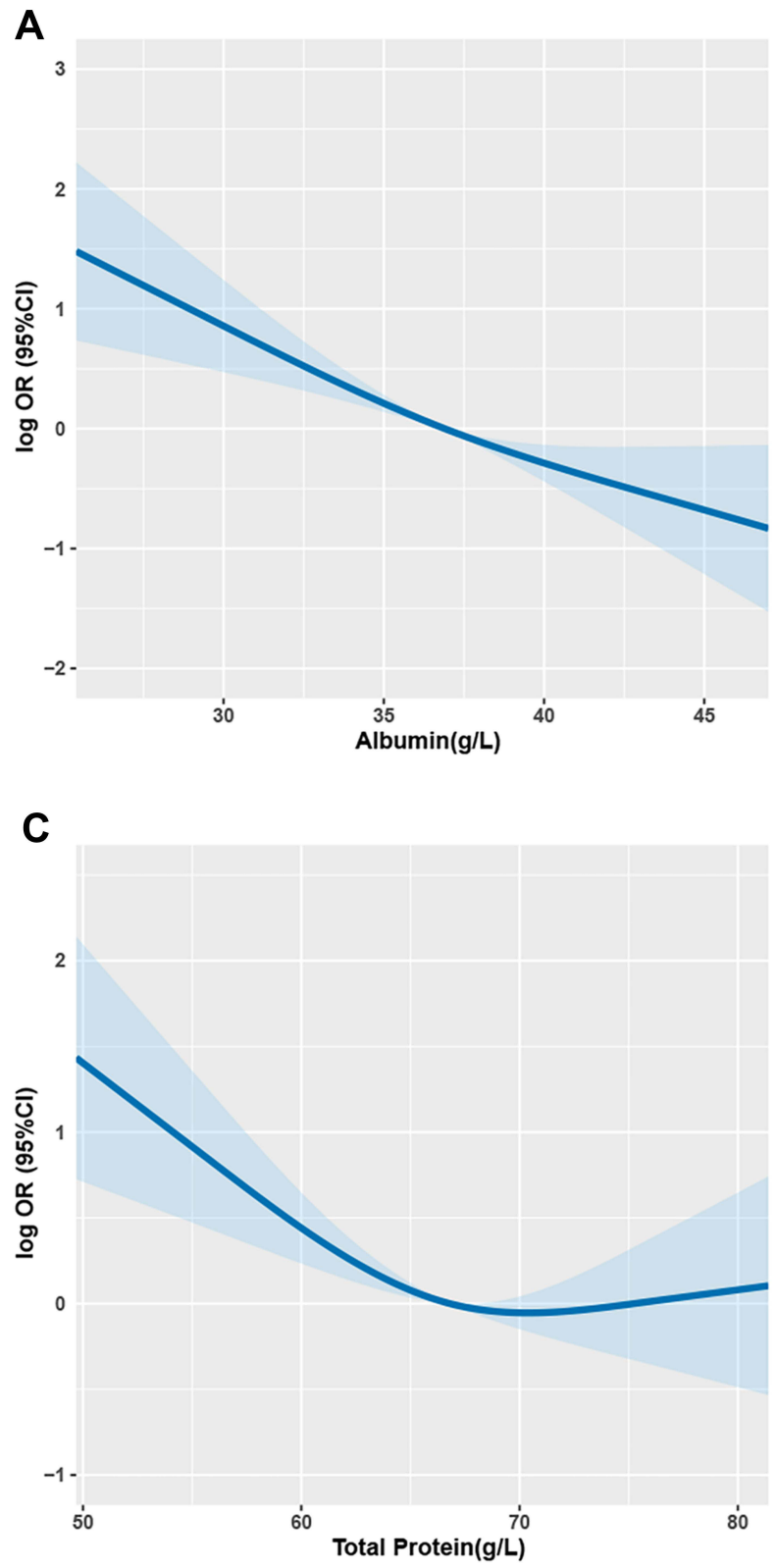

mortality risk leveled off with the increase in total protein in those with total protein $\geq 70.4 \mathrm{~g} / \mathrm{L}$ (Figure $2 \mathrm{C}$ ). When albumin was categorized into quartiles $(\mathrm{Q} 1 \leq 33.1 \mathrm{~g} / \mathrm{L}$, Q2: 33.1-36.9 g/L, Q3: 36.9-40.1 g/L, Q4 >40.1 g/L), the quartiles Q3 (OR: 0.30; 95\% CI: 0.18, 0.50; p<0.001) and Q4 (OR: 0.26; 95\% CI: 0.16, 0.44; p<0.001) had higher 1-year survival rates than those in Q1 (Table 2). When total protein levels were categorized into quartiles (Q1 $\leq 61.8$ g/L, Q2: 61.8-66.8 g/L, Q3: 66.8-71.2 g/L, Q4

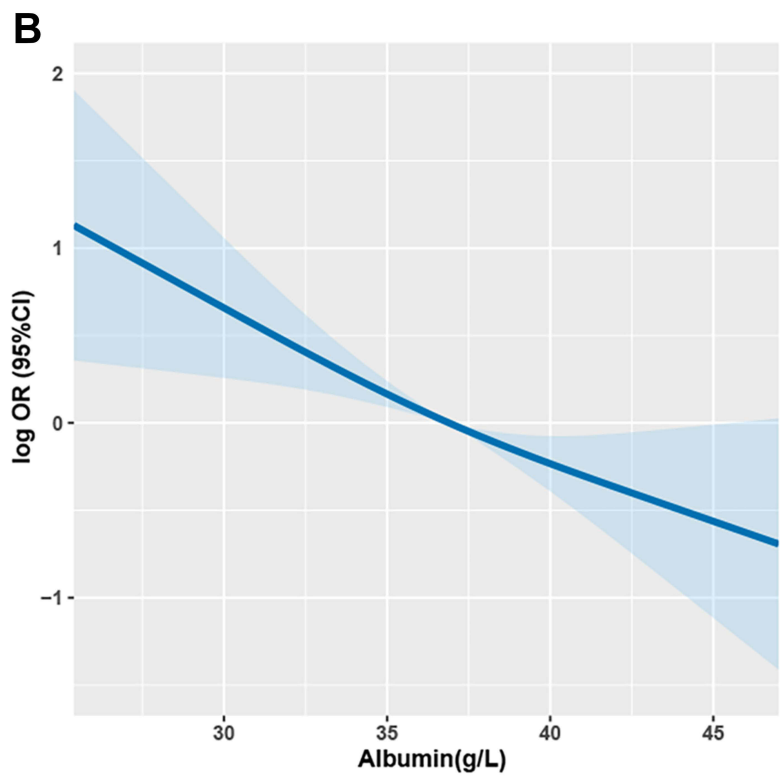

D

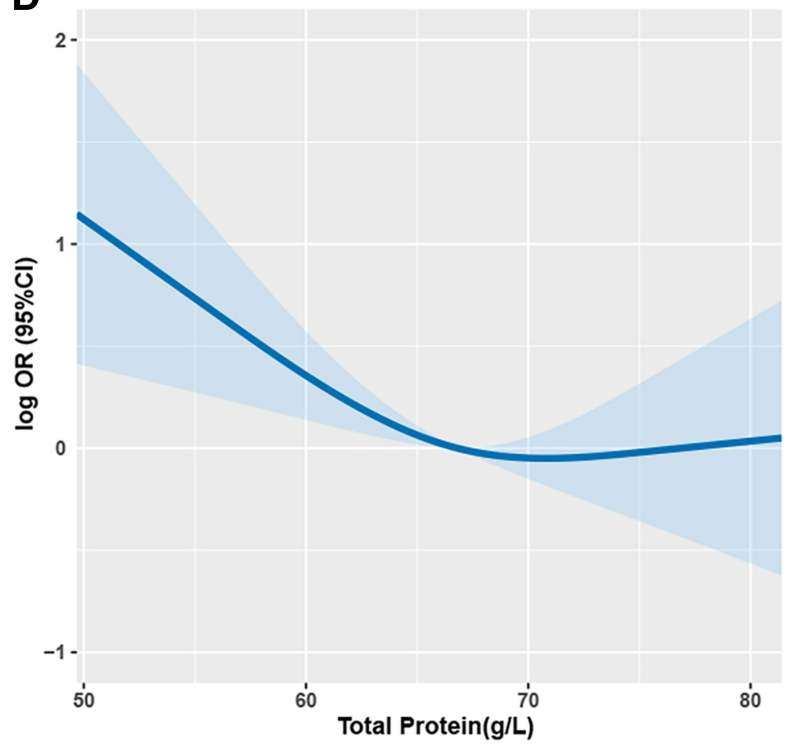

Figure 2 The association of albumin $(\mathbf{A}$ and $\mathbf{B})$ and total protein $(\mathbf{C}$ and $\mathbf{D})$ with I-year survival in patients with cancer cachexia.

Notes: (A) Unadjusted model: p<0.00I; OR: 0.90; 95\% Cl: 0.87,0.93; (B) Adjusted model p<0.00I; adjusted OR: 0.92; 95\% Cl: 0.89,0.95; (C) Unadjusted model: p<0.00I; OR: 0.96; 95\% Cl: 0.94,0.98; (D) Adjusted model $p=0.005$; adjusted OR: 0.97; 95\% Cl: 0.94, 0.99. Adjusted for PLT, lymphocyte count, TSF, treatment, and nutrition support. Abbreviations: PLT, platelet; TSF, triceps skin fold; $\mathrm{Cl}$, confidence interval; OR, odds ratio. 
Table 2 Association of I-Year Survival in Patients with Cancer Cachexia and Albumin Concentration

\begin{tabular}{|c|c|c|c|c|c|}
\hline \multirow[t]{2}{*}{ Albumin (g/L) } & \multirow[t]{2}{*}{ Cases/Controls } & \multicolumn{2}{|c|}{ Unadjusted } & \multicolumn{2}{|c|}{ Adjusted } \\
\hline & & OR (95\% CI) & $P$ value & OR (95\% Cl) & $\mathbf{P}$ value \\
\hline As continue value & $266 / 266$ & $0.90(0.87,0.93)$ & $<0.001$ & $0.92(0.89,0.95)$ & $<0.001$ \\
\hline \multicolumn{6}{|l|}{ Cut-off } \\
\hline$\leq 35 g / L$ & $127 / 69$ & Ref. & & Ref. & \\
\hline$>35 g / L$ & $139 / 197$ & $0.38(0.27,0.55)$ & $<0.001$ & $0.48(0.33,0.7 \mathrm{I})$ & $<0.001$ \\
\hline \multicolumn{6}{|l|}{ Quartiles } \\
\hline QI (s33.1) & $92 / 43$ & Ref. & & Ref. & \\
\hline Q2 (33.I-36.9) & $74 / 58$ & $0.6(0.36,0.98)$ & 0.042 & $0.70(0.4 \mathrm{I}, 1.17)$ & 0.174 \\
\hline Q3 (36.9-40.I) & $52 / 80$ & $0.30(0.18,0.50)$ & $<0.001$ & $0.42(0.25,0.7 \mathrm{I})$ & 0.001 \\
\hline Q4 (>40.I) & $48 / 85$ & $0.26(0.16,0.44)$ & $<0.001$ & $0.35(0.20,0.59)$ & $<0.001$ \\
\hline$P$ for trend & & & $<0.001$ & & $<0.001$ \\
\hline
\end{tabular}

Notes: The ORs for I-year survival in patients with cancer cachexia were estimated by modeling albumin as a continuous variable and as quartiles using conditional logistic regression. Adjusted for PLT, lymphocyte count, TSF, treatment, and nutrition support.

Abbreviations: $\mathrm{Cl}$, confidence interval; $\mathrm{OR}$, odds ratio.

$>71.2 \mathrm{~g} / \mathrm{L}$ ), the quartiles Q2 (OR: 0.36; 95\% CI: 0.22 , $0.59 ; \mathrm{p}<0.001$ ), Q3 (OR: 0.45; 95\% CI: 0.27, 0.74; $\mathrm{p}=0.002$ ), and Q4 (OR: 0.39; 95\% CI: 0.24,0.64; $\mathrm{p}=<0.001$ ) had higher 1-year survival rates than those in Q1 (Table 3).

\section{Subgroup Analyses}

The relationship of albumin and total protein (as continuous variables) with 1-year survival in different subgroups was assessed using stratified analysis. In the subgroup analysis, Hb levels ( $p$ for interaction $=0.031$ ) and HGS ( $p$ for interaction=0.009) significantly modified the protective effects associated with serum albumin levels (Figure 3A).
HGS significantly ( $p$ for interaction $=0.023$ ) modified the protective effects associated with total protein levels (Figure 3B). None of the other stratified variables significantly modified the relationship of albumin and total protein with 1-year mortality $(\mathrm{p}>0.05)$.

\section{Analysis of All Cancer Patients}

We performed Kaplan-Meier survival analysis stratified by albumin and total protein levels for the overall population with cancer cachexia. The results showed that patients with high albumin levels had a better survival probability (Figure 4A). Similar results were found in the total protein-based analysis (Figure 4B).

Table 3 Association of I-Year Survival in Patients with Cancer Cachexia and Total Protein Concentration

\begin{tabular}{|c|c|c|c|c|c|}
\hline \multirow[t]{2}{*}{ Total Protein (g/L) } & \multirow[t]{2}{*}{ Cases/Controls } & \multicolumn{2}{|c|}{ Unadjusted } & \multicolumn{2}{|c|}{ Adjusted } \\
\hline & & OR (95\% Cl) & $P$ value & OR (95\% Cl) & $P$ value \\
\hline As continue value & $266 / 266$ & $0.96(0.94,0.98)$ & $<0.001$ & $0.97(0.94,0.99)$ & 0.005 \\
\hline $\begin{array}{l}\text { Cut-off } \\
\qquad 60 \mathrm{~g} / \mathrm{L} \\
>60 \mathrm{~g} / \mathrm{L}\end{array}$ & $\begin{array}{c}71 / 34 \\
195 / 232\end{array}$ & $\begin{array}{c}\text { Ref. } \\
0.4(0.26,0.63)\end{array}$ & $<0.001$ & $\begin{array}{c}\text { Ref. } \\
0.49(0.30,0.79)\end{array}$ & 0.003 \\
\hline $\begin{array}{l}\text { Quartiles } \\
\text { QI ( } \leq 61.8) \\
\text { Q2 (6I.8-66.8) } \\
\text { Q3 (66.8-7I.2) } \\
\text { Q4 (>7I.2) }\end{array}$ & $\begin{array}{l}90 / 45 \\
56 / 78 \\
62 / 69 \\
58 / 74\end{array}$ & $\begin{array}{c}\text { Ref. } \\
0.36(0.22,0.59) \\
0.45(0.27,0.74) \\
0.39(0.24,0.64)\end{array}$ & $\begin{array}{c}<0.001 \\
0.002 \\
<0.001\end{array}$ & $\begin{array}{c}\text { Ref. } \\
0.38(0.23,0.64) \\
0.59(0.35,1.01) \\
0.46(0.27,0.78)\end{array}$ & $\begin{array}{c}<0.001 \\
0.056 \\
0.004\end{array}$ \\
\hline$P$ for trend & & & 0.001 & & 0.03 \\
\hline
\end{tabular}

Notes: The ORs of I-year survival in patients with cancer cachexia were estimated by modeling total protein as a continuous variable and as quartiles using conditional logistic regression. Adjusted for PLT, lymphocyte count, TSF, treatment, and nutrition support.

Abbreviations: $\mathrm{Cl}$, confidence interval; OR, odds ratio. 

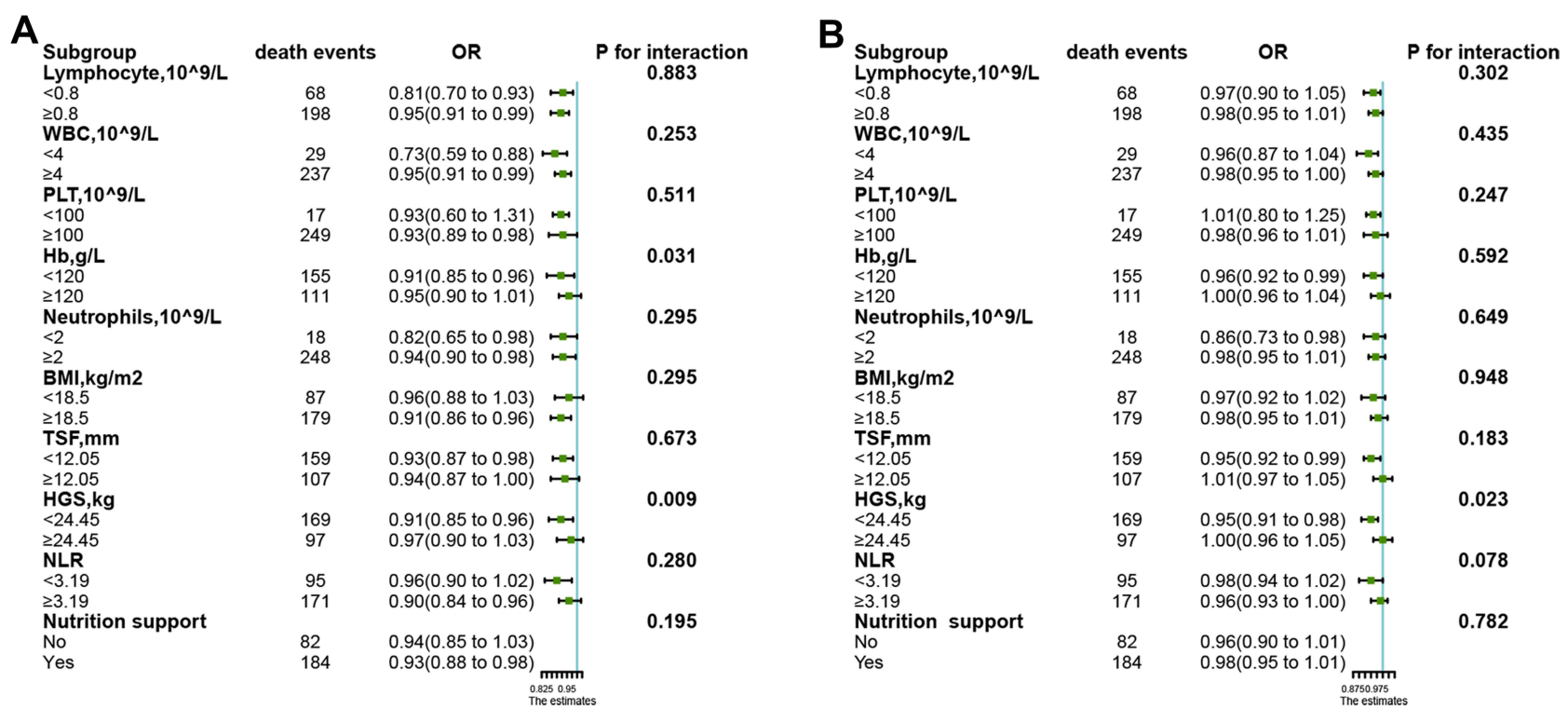

Figure 3 The association of albumin (A) and total protein (B) with the risk of I-year survival in patients with cancer cachexia in various subgroups. Notes: The albumin and total protein were analyzed as continuous variables. Adjusted for PLT, lymphocyte count, TSF, treatment and nutrition support. Abbreviations: Hb, hemoglobin; WBC, white blood cell; RBC, red blood cell; PLT, platelet; BMI, body mass index; MAC, mid-arm circumference; TSF, triceps skin fold; HGS, handgrip strength; CC, calf circumference.

A

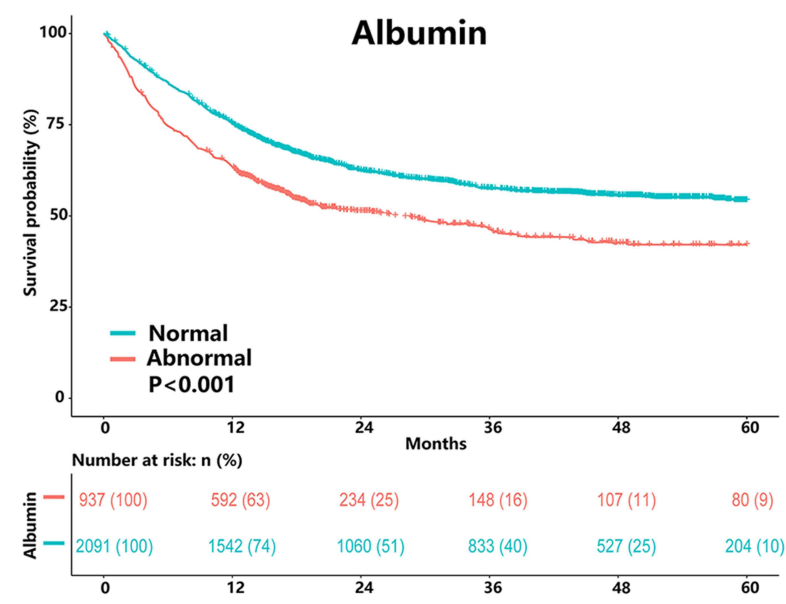

B

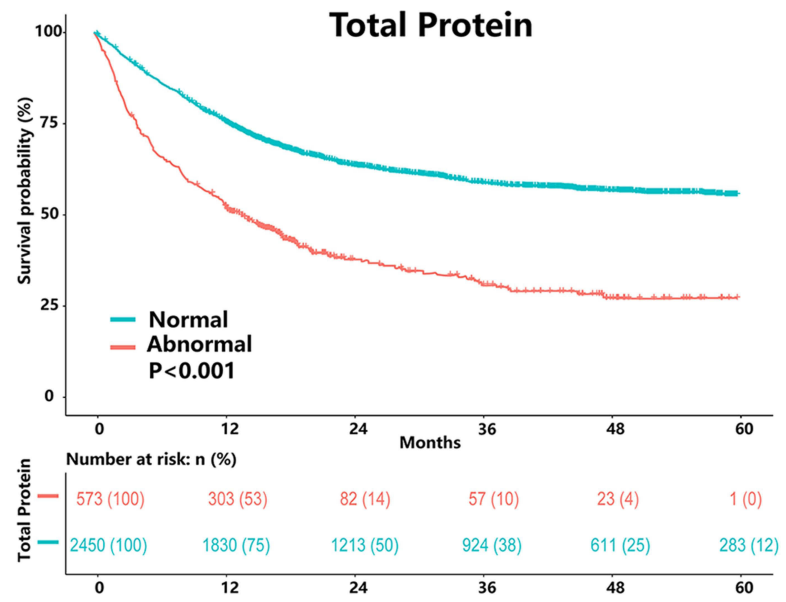

Figure 4 Results of the Kaplan-Meier survival analysis for patients with cancer cachexia stratified by albumin (A) and total protein (B) based on all patients with cancer cachexia.

Notes: (A) Based on all patients with cancer cachexia $(n=3032)$. (B) Based on all patients with cancer cachexia $(n=3027)$.

\section{Discussion}

In this nested case-control study, we observed a significant negative linear association between albumin level and 1-year mortality in patients with cancer cachexia. There was an L-shaped relationship between total protein and 1-year mortality, with a turning point around $70.4 \mathrm{~g} / \mathrm{L}$. The association between albumin level and prognosis in patients with cancer cachexia has been previously examined in several studies; however, the findings were inconsistent.
Our study results are consistent with those reported by Naumann et al who found that chemoradiation-induced decrease in albumin was linked to poor prognosis in patients with cancer cachexia. ${ }^{13}$ Matsuzuka et al suggested that serum albumin was a prognostic factor for treatment outcomes and compliance in patients with locally advanced chemoradiotherapy for head and neck squamous cell carcinoma. $^{7}$ Bland et al found that albumin as a continuous variable significantly predicted improved 
overall survival in patients with cancer cachexia patients, where an additional $1 \mathrm{~g} / \mathrm{L}$ increase in albumin reduced the risk of death by $7 \% .{ }^{14}$ In our analysis, we found similar results, whereby patients with low serum albumin concentrations had significantly higher 1-year mortality rates than those with high serum albumin concentrations.

Srdic et al also showed that albumin concentration with an established cutoff point of $37.5 \mathrm{~g} / \mathrm{L}$ was clearly proven to be a predictive factor for both chemotoxicity and survival in patients with diagnosed advanced non-small cell lung cancer (NSCLC) stage IIIB and IV. ${ }^{15}$ Jouinot et al demonstrated that albumin level was an independent prognostic factor in metastatic non-small cell lung cancer. ${ }^{16}$ Additionally, Vigano et al established serum albumin as a reliable and clinically viable classification criterion for cancer cachexia in patients with advanced malignancy. ${ }^{17}$

Interestingly, Brkic et al found no apparent relationship between low serum albumin levels before treatment and overall survival (OS) or disease-free survival (DFS) in patients with sinusoidal squamous cell carcinoma. ${ }^{18}$ Such inconsistent findings may be due to differences in population characteristics, study outcomes, or type of tumor, which need to be explored further.

Our study found that $\mathrm{Hb}$ and HGS could modify the protective effect of albumin on the survival of patients with cachexia. One possible explanation is that $\mathrm{Hb}$ may be an indicator of nutritional status, when the concentrations of $\mathrm{Hb}$ and albumin are both low, the prognosis of patients with cachexia are worse. ${ }^{15}$ Zhuang et al showed that cancer patients with low HGS were shown to be correlated with lower serum albumin concentration. ${ }^{19}$

The advantage of our study was that the nested casecontrol study excluded any influence exerted by factors such as hospital, tumor type and stage, age, and sex. However, our study has several limitations. Since the study was retrospective, some anthropometric measurements were not available, which may have resulted in a selection bias. Second, although some potential confounders were adjusted, the results may have been influenced by factors that were not accounted for or measured. Therefore, studies from different geographically localized centers are needed to reinforce the universality of our findings and further evaluate the risk or benefit of monitoring protein levels for predicting mortality risk.

\section{Conclusion}

The results of this study suggest that serum albumin might be a good variable for predicting 1-year survival, especially in patients with lowHb or HGS. An L-shaped association between serum total protein levels and the risk of 1-year mortality among patients with cancer cachexia was observed, with a turning point at approximately 70.4 $\mathrm{g} / \mathrm{L}$, while HGS significantly modified the protective effects associated with total protein levels.

Our study will potentially stimulate future clinical studies to gain a more comprehensive understanding of the effects of serum protein levels in patients with cancer cachexia.

\section{Availability of Supporting Data}

The datasets used and/or analyzed during the current study are available from the corresponding author upon reasonable request.

\section{Ethics Approval and Consent to Participate}

This study was carried out in accordance with the ethical standards of the Helsinki Declaration and approved by the Medical Ethics Committee of First Affiliated Hospital of Sun Yat-sen University (assurance number: Medical research ethics review (2013) No. 82), and registered in the Chinese Clinical Trial Registry (NO ChiCTR1800020329, http://www.chictr.org.cn/). All participants provided written informed consent.

\section{Consent for Publication}

Consent for publication was obtained from all co-authors.

\section{Acknowledgments}

We would like to thank Hong-yun Shi, Wei Li, Fu-xiang Zhou, Ming Liu, Ming-hua Cong for their contributions to the work. We would like to thank Editage for English language editing.

\section{Author Contributions}

All authors contributed to data analysis, drafting or revising the article, have agreed on the journal to which the article will be submitted, gave final approval of the version to be published, and agree to be accountable for all aspects of the work.

\section{Funding}

This work was supported by the National Key Research and Development Program (2017YFC1309200). 


\section{Disclosure}

The authors report no conflicts of interest in this work.

\section{References}

1. Fearon K, Strasser F, Anker SD, et al. Definition and classification of cancer cachexia: an international consensus. Lancet Oncol. 2011;12 (5):489-495. doi:10.1016/S1470-2045(10)70218-7

2. Schmidt SF, Rohm M, Herzig S, Berriel Diaz M. Cancer cachexia: more than skeletal muscle wasting. Trends Cancer. 2018;4 (12):849-860. doi:10.1016/j.trecan.2018.10.001

3. Evans WJ, Morley JE, Argiles J, et al. Cachexia: a new definition. Clin Nutr. 2008;27:793-799. doi:10.1016/j.clnu.2008.06.013

4. Penet MF, Bhujwalla ZM. Cancer cachexia, recent advances, and future directions. Cancer J. 2015;21(2):117-122. doi:10.1097/ PPO.0000000000000100

5. Cong $\mathrm{M}$, Song $\mathrm{C}, \mathrm{Xu} \mathrm{H}$, et al.; Investigation on Nutrition Status and Clinical Outcome of Common Cancers (INSCOC) Group. The patient-generated subjective global assessment is a promising screening tool for cancer cachexia. BMJ Support Palliat Care. 2020. doi:10.1136/bmjspcare-2020-002296

6. Gatta A, Verardo A, Bolognesi M. Hypoalbuminemia [J]. Intern Emerg Med. 2012;7 Suppl 3:S193-9. doi:10.1007/s11739-012-0802-0.

7. Matsuzuka T, Kiyota N, Mizusawa J, et al.; Japan Clinical Oncology Group (JCOG) Head and Neck Cancer Study Group. Clinical impact of cachexia in unresectable locally advanced head and neck cancer: supplementary analysis of a Phase II trial (JCOG0706-S2). Jpn J Clin Oncol. 2019;49(1):37-41. doi:10.1093/jjco/hyy145

8. $\mathrm{Xu} \mathrm{H}$, Song $\mathrm{C}$, Wang $\mathrm{C}$, et al. Investigation on nutrition status and clinical outcome of patients with common cancers in Chinese patients: a multicenter prospective study protocol. Int J Clin Trials. 2020;7(2):94. doi:10.18203/2349-3259.ijct20201052

9. Amin MB, Greene FL, Edge SB, et al. The Eighth Edition AJCC Cancer Staging Manual: continuing to build a bridge from a population-based to a more "personalized" approach to cancer staging. CA Cancer J Clin. 2017;67(2):93-99. doi:10.3322/caac.21388

10. Santos DA, Dawson JA, Matias CN, et al. Reference values for body composition and anthropometric measurements in athletes [J]. PLoS One. 2014;9(5):e97846. doi:10.1371/journal.pone.0097846. eCollection 2014.
11. Bueno H, Ross JS, Wang Y, et al. Trends in length of stay and shortterm outcomes among Medicare patients hospitalized for heart failure, 1993-2006. JAMA. 2010;303(21):2141-2147. doi:10.1001/ jama.2010.748

12. Keller U. Nutritional laboratory markers in malnutrition. J Clin Med. 2019;8(6):775. doi:10.3390/jcm8060775

13. Naumann P, Eberlein J, Farnia B, et al. Cachectic body composition and inflammatory markers portend a poor prognosis in patients with locally advanced pancreatic cancer treated with chemoradiation. Cancers (Basel). 2019;11(11):1655. doi:10.3390/ cancers 11111655

14. Bland KA, Zopf EM, Harrison M, et al. Prognostic markers of overall survival in cancer patients attending a cachexia support service: an evaluation of clinically assessed physical function, malnutrition and inflammatory status. Nutr Cancer. 2020;1-11. doi:10.1080/ 01635581.2020.1800765.

15. Srdic D, Plestina S, Sverko-Peternac A, Nikolac N, Simundic AM, Samarzija M. Cancer cachexia, sarcopenia and biochemical markers in patients with advanced non-small cell lung cancer-chemotherapy toxicity and prognostic value. Support Care Cancer. 2016;24 (11):4495-4502. doi:10.1007/s00520-016-3287-y

16. Jouinot A, Ulmann G, Vazeille C, et al. Hypermetabolism is an independent prognostic factor of survival in metastatic non-small cell lung cancer patients. Clin Nutr. 2020;39(6):1893-1899. doi:10.1016/j.clnu.2019.08.003

17. Vigano AAL, Morais JA, Ciutto L, et al. Use of routinely available clinical, nutritional, and functional criteria to classify cachexia in advanced cancer patients. Clin Nutr. 2017;36(5):1378-1390. doi:10. 1016/j.clnu.2016.09.008

18. Brkic FF, Kadletz L, Jank B, Mayer C, Heiduschka G, Brunner M. Impact of pretherapeutic neutrophil-to-lymphocyte ratio, serum albumin, body-mass index, and advanced lung cancer inflammation index on clinical outcome in sinonasal squamous cell carcinoma. J Craniomaxillofac Surg. 2020;48(1):33-37. doi:10.1016/j.jcms.20 19.11.010

19. Zhuang CL, Zhang FM, Li W, et al. Associations of low handgrip strength with cancer mortality: a multicentre observational study. J Cachexia Sarcopenia Muscle. 2020;11(6):1476-1486. doi:10.10 02/jcsm. 12614

\section{Publish your work in this journal}

Cancer Management and Research is an international, peer-reviewed open access journal focusing on cancer research and the optimal use of preventative and integrated treatment interventions to achieve improved outcomes, enhanced survival and quality of life for the cancer patient.
The manuscript management system is completely online and includes a very quick and fair peer-review system, which is all easy to use. Visit http://www.dovepress.com/testimonials.php to read real quotes from published authors. 